\title{
Overcoming judgmental biases in negotiations: a scenario-based survey analysis on third party direct intervention
}

\author{
In press: Journal of Business Research \\ Andrea Caputo \\ Lincoln Business School, \\ University of Lincoln, \\ Brayford Pool, Lincoln, LN6 7TS, United Kingdom, \\ email: acaputo@lincoln.ac.uk, \\ phone: $+44(0) 1522835621$
}

\begin{abstract}
In many business negotiations, negotiators fail to identify and consequently exploit the integrative potential that underlies their interests and positions, due to cognitive biases preventing clear information processing. Such biases can be overcome through the intervention of external parties. This study explores perceptions of a new form of external intervention un negotiations to overcome cognitive biases and reach integrative agreements: third party direct intervention. This study contributes first to the understanding of challenges and solutions to reaching integrative agreements; second, to increasing knowledge about individual differences in negotiation; third, to developing a novel methodological approach to study negotiations by creating and validating a case scenario using vignettes. Based on data collected from a sample of fifty-six experienced managers, findings show that this form of intervention increased the creation of value, fairness and the likelihood of reaching an agreement. Individual differences were found in terms of personality traits, gender, and education.
\end{abstract}

Keywords: Integrative Negotiation, Cognitive Bias, Third Party, Individual differences, Managers 


\section{Overcoming judgmental biases in negotiations: a scenario-based survey analysis on third party direct intervention}

\section{Introduction}

As businesses and their managers are increasingly engaging in negotiations of strategic importance due to the growing pressures from the economic downturn and globalized competition, they need to understand how to create and deliver value to a broader set of parties involved in such negotiations. This means reaching agreements that offer win-win solutions to an enlarged and diverse audience, which often includes stakeholders at large. For example, in 2009 Fiat, the Italian carmaker, decided to partner with Chrysler, an almost bankrupt firm at that time. They had to negotiate with a large and heterogeneous set of parties which included stakeholders such as the US Government and the Unions, to integrate contending interests and finally find a win-win agreement who not only saved both companies from a deep crisis but also allowed them to create a competitive advantage (Caputo, 2015). This type of negotiation is called integrative or win-win due to the possibility, if successful, of benefiting all parties involved through a higher joint gain (Lewicki, Saunders, \& Barry, 2014; Ogliastri \& Quintanilla, 2016). Understanding how integrative agreements, and consequently higher profit and satisfaction, can be achieved in negotiations would have a significant impact not only for organizations and their stakeholders, but also for the global economy as a whole.

Although most negotiations are seen to include the potential for achieving integrative solutions, from both a theoretical and practical perspective such solutions are traditionally considered to be highly complex to achieve (Lewicki et al., 2014). Such complexities often arise due to the arithmetic of negotiations, that is the addition and subtraction of parties, issues and interests within a negotiation (Sebenius, 1983). Indeed, integrative negotiations often involve multiple issues and parties, which per se complicates the relationships and the reaching of an agreement (Kramer, 1991). Thus, behavioral researchers have revealed that negotiators are often inefficient in the sense that they fail to reach integrative agreements, although these agreements are frequently available, mutually beneficial, and therefore desirable solutions (Moran \& Ritov, 2007; Neale \& Bazerman, 1991). Recent literature reviews (Caputo, 2013a; Thompson, Nadler, \& Lount, 2006) evidenced that the main reasons for such inefficiencies reside in the negotiators' inability to see the integrative potential due to the interplay of several cognitive heuristics that 
bias negotiators' judgment and decision-making (Larrick \& Wu, 2007; Neale \& Bazerman, 1991; Zartman, 2008).

It remains ambiguous how negotiators can overcome cognitive and judgmental biases (Caputo, 2013a) and among the many proposed solutions a recurrent one is the inclusion of external views at the table. This is often achieved through mediation (Stevens, 1963) and facilitation (Walton \& McKersie, 1965), processes typical of the third party dispute resolution approach (Lewicki, Weiss, \& Lewin, 1992), where parties external to a conflict take actions to resolve it or restore effective negotiation. Idiosyncratic of such interventions is the displacement of interests, as the third party — acting as a consultant — is more interested in reaching any agreement than reaching a good and lasting agreement (Lewicki et al., 1992). Another approach calls for the intervention of parties with more tangible and stronger interests in the achievement, implementation and consequences of a negotiated agreement, parties that transition from external to internal by joining the negotiations (Sebenius, 1983). For the purpose of this study, such an approach is referred as third party direct intervention, where a third party is originally a stakeholder to the negotiation — a social stakeholder, a potential industrial partner, or a competitor — who joins it as a party (Caputo, 2013b).

In a recent review of the literature, Caputo (2013a) highlighted that, although most negotiations in business and political context have a potential for creating value and are performed by more than two parties, the role of biases in integrative negotiations and multilateral negotiations was under-researched in the literature, concluding that further research should investigate how bringing in new parties could help de-bias the negotiation process. Indeed, despite a growing and multidisciplinary interest of research in integrative negotiations (Caputo, 2012; Harinck \& De Dreu, 2004; Schei, 2008; Traavik, 2011), most research in negotiation focuses on distributive bargaining in two party settings, often through controlled experiments with student samples (Chan \& Ng, 2016; Giacomantonio, De Dreu, \& Mannetti, 2010; Patton \& Balakrishnan, 2010; Traavik, 2011). Often in conference presentations, when asked about the limitations of such an approach, these researchers' main justification is related to the complexities of analyzing integrative negotiations, where a multitude of parties, issues and interests are at stake (Kramer, 1991). Such an approach has been widely criticized in literature on multiple occasions (Herbst \& Schwarz, 2011; Pruitt, 2011), and a few studies have started to investigate negotiations in a closer-to-reality fashion (Ness \& Haugland, 2005; Ogliastri \& 
Quintanilla, 2016; Volkema, 2004). In line with such a stream of research, this study proposes a novel theoretical and methodological approach to investigating managers' perceptions of the direct intervention of a third party through the original development of a case scenario. Specifically, this article aims at answering the following research questions: can third party direct intervention help in overcoming biases in negotiations? How do managers perceive this role? Do managers and negotiators perceive this form of cooperation as fair and effective? In doing so, the study contributes to the development of a more practical approach to studying negotiation and to a better understanding of the process of adding parties to a strategic negotiation to achieve an integrative agreement.

The next section presents the theoretical background and propositions being tested. The methodology section is followed by the presentation of results and discussion of the main findings. Finally, conclusions and implications for future research are addressed.

\section{Background and propositions}

\subsection{Integrative Negotiations}

Negotiation is commonly defined as a process through which two or more parties reach a needed joint decision, while having different interests and preferences (Lax \& Sebenius, 1986; Raiffa, Richardson, \& Metcalfe, 2002). Due to the interdependence that takes place in multiactor decision processes (Lewicki et al., 2014), negotiation processes and outcomes are affected by all decisions made by all the parties involved, which contain their individual differences, attitudes, prejudices and assumptions (Chan \& Ng, 2016). Negotiations are different from other group decision making processes because parties are driven by both the motivation to achieve their own interests and, at the same time, by a we-rationality needed to cooperate with the other party to reach a joint decision (Traavik, 2011). The process is replete with dilemmas, and the parties involved consistently misinterpret the situation or their counterparts' interests (Caputo, 2013a). In doing so, they may be motivated to approach the negotiation with a more competitive mind-set, using influence tactics and misleading behaviors, treating the situation as distributive.

Traditionally, negotiations have been categorized as distributive and integrative, on the basis of the characteristics of the process and outcome. Negotiation processes include negotiators' behaviors, tactics, attitudes, cognitions, emotions and motivations; while negotiation 
outcomes include the features of the agreement (see Lewicki et al., 2014 for a close examination of the subject). Distributive negotiations, also known as win-lose or fixed-sum, refer to the joint decision making process to distribute scarce resources among the parties involved. The negotiation process is usually competitive in nature; negotiators have diametrically opposed interests and attempt to get the larger share, such as an amount of raw material, money or the like, by deploying win-lose strategies and tactics. The purpose of the negotiation is to claim value, that is to do whatever it takes to claim the largest piece of the resources (Lax \& Sebenius, 1986). A classic example is the ultimatum game (Güth, Schmittberger, \& Schwarze, 1982), where two parties have to agree on how to divide a fixed sum of money. In contrast, integrative negotiations, also known as win-win or variable-sum, refer to a situation where it is possible for the parties involved to achieve their goals simultaneously. The negotiation process is usually collaborative and aimed at problem solving; often interests and goals are linked "so that one person's goal achievement helps others to achieve their goals" (Lewicki et al., 2014, p. 11) and the agreement "incorporates, and reconciles, the parties' interests and produces high joint benefit" (Traavik, 2011, p. 192). The purpose of the negotiation is to create value (Lax \& Sebenius, 1986), that is to do whatever it takes to meet mutual objectives, either by identifying more resources or finding unique ways to reconfigure, share or coordinate the use of available resources (Lewicki et al., 2014). It is generally said that most real negotiations contain the possibility of reaching an integrative agreement (Lewicki et al., 2014; Traavik, 2011). Moreover, integrative agreements, by providing higher joint outcomes, satisfaction and quality process, are considered to be preferable in business negotiations where a long-term relationship is particularly important (Lewicki et al., 2014). At the same time and despite the academic, professional, and educational efforts, integrative agreements are highly difficult to reach (Lewicki et al., 2014). Why do negotiators often fail to reach them? A possible explanation comes from the studies on bounded rationality (Simon, 1972) and the subsequent cognitive biases which alter the decision making processes of negotiators.

\subsection{Cognitive biases in Negotiations}

Stemming from Herbert Simon's work, a wide body of literature has addressed the issue of cognitive biases affecting decision-making processes, trying to explain why human misperceptions can occur. According to cognitive studies (e.g., Neale \& Bazerman, 1985; 
Thompson \& Hastie, 1990), negotiation processes can be better understood when they are viewed as cognitive decision-making tasks, where individuals construct mental representations of the conflict situation, the issues, and the other parties' positions. This involves the examination of how negotiators' information-processing capabilities influence negotiators' judgment formation and behavioral processes. In this regard, the aim is to identify the faulty assumptions of negotiators' cognition during negotiation processes.

Individuals use rules of thumb, or heuristics, to help themselves make judgments. Newell and Simon (1972) defined the heuristics as those cognitive shortcuts that the human brain tends to use when its decision-making process is limited in terms of time and availability of data. Although they can be very helpful, their use often produces incorrect or partially correct judgments due to systematic biases (Bazerman \& Moore, 2013). A recent systematic literature review identified that only 11 biases have been studied with reference to negotiation contexts (see Caputo, 2013a for a close examination of the subject). For example, Thompson and Hastie (1990) identified the fixed-pie bias, where negotiators inaccurately assume their counterparts' interests are diametrically opposed to their own, even when they are not. This fixed-pie perception often concludes with a faulty decision because most situations provide an opportunity for joint gain. How can negotiators be helped to overcome judgmental biases that prevent them from reaching integrative agreements?

\subsection{The Third Direct Party Intervention}

A possible solution to negotiators' inefficiencies is the external intervention of a party that would bring novel issues and approaches to help negotiators achieve integrative solutions (e.g., Caputo, 2013a). Sebenius (1983) was among the first to theorize the addition or subtraction of parties at the negotiators' table to move the dynamics among interests toward a clearer path for an integrative solution. His central proposition was that issues and parties should not be regarded as static elements but instead as dynamic variables. On the one hand, dynamism is an implicit and natural evolution of the process itself; on the other, the parties can strategically guide it. This manipulation, known as Negotiation Arithmetic, lets parties change the elements of the structure in a strategic way. Similarly, the third party dispute resolution approach, which has been stimulated by concerns about more effective resolution of labor and international disputes (Jackson, 1952), studies the actions taken by parties external to a conflict to resolve it or to 
restore effective negotiation (Lewicki et al., 1992). In this case, external mediators and facilitators can intervene, as consultants, to assist parties to negotiate.

The main difference between the approach of Sebenius and third party dispute resolution is related to the interests of the intervening party. In the latter, the parties are totally external, do not have a strong partisan position on the substantive issues in dispute and have their interests rooted in the execution of a consulting activity. While in the former, the external party soon becomes an internal party, joining the negotiation and having a strong interest in the negotiation outcome and process. For the purpose of this study, we call such an approach Third Party Direct Intervention $(T P D I)$, defined as a situation where parties originally external to a negotiation enter the negotiation with a strong interest in the achievement, implementation and consequences of an agreement (Caputo, 2013b). In this sense, a third party is a stakeholder to the negotiation; for example, they can be a social stakeholder of the company, a potential industrial partner, or a competitor.

A primary justification for a third party to have a strong interest in the solution of the conflict has been addressed by Karambayya and Brett (1989). They focused on perceptions of fairness and the role of managers in handling disputes, demonstrating negative outcomes when disputants worked the conflict out themselves. Regarding third party dispute resolution, Keashly et al. (1993) stressed how mediators, for example, were also found to be subject to cognitive biases and limitations in achieving integrative solutions, they emphasized how the parties themselves have difficulties in shifting their thinking and behavior towards a collaborative, winwin orientation. More recently, Ackermann and Eden (2011) found a positive correlation between the introduction of a subject capable of helping collective cognition and an agreement's implementation and stability. Therefore, it is proposed:

Proposition 1: The TPDI should be associated with a less biased interpretation of information.

Proposition 2: The TPDI should be associated with an increase in the perception of fairness of information disclosure.

The key determinant for the success of the third party intervention appears to be the possible linkages between the interests of the newly formed set of parties as a consequence of the intervention. Indeed, it has been found that encouraging the entry of these parties is likely to reinforce existing coalitions or help to form one, thanks to leverage due to links with new 
interests and issues (Murninghan \& Brass, 1991; Raiffa et al., 2002). Thus, it is proposed that as a result of the strategic addition of parties the negotiation can benefit thanks to connections between issues and interests. This view identifies that the addition of parties to the negotiation can be beneficial provided they have tangible interests or can materially influence the negotiation. Such an intervention, by stimulating the adoption of behaviors aimed at a creating value perspective, allows the negotiations to move from a distributive setting to an integrative setting. Therefore, it is proposed:

Proposition 3: The TPDI should be associated with a higher creating value approach rather than claiming value.

Proposition 4: The TPDI should be considered to be helpful to overcome judgmental biases.

Proposition 5: The TPDI should be considered to be helpful to reach a negotiated solution.

Proposition 6: TPDI should be associated with higher confidence in the possibility of reaching a negotiated solution.

\section{- - - PLEASE INSERT FIGURE 1 ABOUT HERE - - -}

\subsection{Individual differences}

For the purpose of this study, individual differences are referred to differences in demographics (i.e. gender, education, and experience) and personality factors. Personality has been defined as "consistency over time in a person's behaviors when that individual is placed again in the same situation" (Sharma, Bottom, \& Elfenbein, 2013, p. 301). The personality factors that make up the "Big Five" are dispositional categories under which a variety of specific traits may be subsumed (Barry \& Friedman, 1998). According to Barrick and Mount (1991), these five factors include: extraversion, which is associated with being sociable, assertive, talkative and active; agreeableness, which is associated with being courteous, flexible, trusting, co-operative and tolerant; conscientiousness, which is associated with being careful, responsible and organized; emotional stability, which is associated with being calm, even-tempered, and less likely to feel tense or rattled; openness to experience, which is associated with being imaginative, curious, original and open-minded. 
The stream of studies on individual differences in negotiation has a long and contradictory history, it led to an irrelevance consensus of a limited role of such differences, which has been considered to stem from an early narrative based on limited data (Sharma et al., 2013).

Researchers have examined the impact of individual differences on negotiation processes and outcomes on several occasions (e.g., Thompson \& Hastie, 1990; Volkema, 2004). Thompson (1990), in a review of the literature on negotiation behavior and outcomes, claimed that personality and individual differences played a minimal role in determining bargaining styles and outcomes in dyadic negotiations. The impact of personality on negotiation has not been adequately studied, and researchers may have prematurely dismissed personality effects as topics for research (Barry \& Friedman, 1998; De Dreu, 2003; Sharma et al., 2013; Volkema, 2004). In a meta-analysis based on more than a thousand articles, Sharma and colleagues (2013) argued and demonstrated that the consensus is paradoxical and premature, due to the vast research "demonstrating the predictive power of individual difference variables across a wide range of other organizational settings" (p. 294). By analyzing a wide range of individual difference variables, including personality, emotional intelligence and risk propensity, they concluded by recognizing the "potentially far-reaching role of individual differences in predicting negotiation outcomes" (p. 322). It is reasonable to assume that personality influences negotiation processes since people exhibit a great deal of consistency across situations, which suggests that personality is an important influence on social behavior. Therefore, it is proposed:

Proposition 7: Individual differences should be found in terms of personality, education and experience, on perceptions about the negotiation process and TPDI.

Proposition 8: Individual differences should be found in terms of personality, education and experience, on perceptions about the negotiation outcome and TPDI.

\section{Methodology}

\subsection{Aim and design of the study}

This study aims at investigating whether a third party direct intervention can help overcome negotiators' biases through managers' perceptions of such an intervention. The study sought a method that would use real managers, would not be influenced by prior respondent behavior and would allow isolating focal constructs. Hence, an experimental task was chosen. 
The task involved participants being presented with a fictional case study, in the form of vignettes that represented a negotiation between two companies, with an external party intervention later in the story, and then being asked to respond to questions related to their perceptions of the situation. The study has been designed to research the issue on two different levels. On the one hand, the analysis covers the general idea of the third party effect on the negotiation. On the other hand, the analysis covers how answers might differ across different subjects, in terms of background education and experience, gender, and personality traits.

\subsection{Development and pilot of the Case Study}

A fictional case study involving a negotiation between two companies and a public institution, the third party, has been originally developed and validated by borrowing the validation technique suggested for scenario-based role playing experiments using vignettes (Rungtusanatham, Wallin, \& Eckerd, 2011). Indeed, this study developed a series of vignettes to convey scripted information about the fictional negotiation taking place. The three stages of constructing a vignette were adopted, i.e. predesign, design and validation (Rungtusanatham et al., 2011).

Predesign stage. In the predesign stage, the focus was the empirical context in which participants would be embedded. The empirical context had to fulfill the following criteria: (a) the negotiation should take place in a business context; (b) the negotiation should include the possibility of achieving an integrative agreement; (c) negotiators should show cognitive biases that prevent them from identifying the integrative solution and mean they reach an impasse; (d) an originally external party (TPDI) should enter the negotiation with a strong interest in reaching a solution; (e) the TPDI should show the original two negotiators the viability of the integrative agreements; (f) the story should be open-ended to allow participants to make a decision. The context of two companies negotiating a merger and the intervention of the local government to facilitate the negotiation was chosen as the context. This situation is similar to the negotiation between Fiat, Chrysler and the US Government in 2009 (Caputo, 2012).

Design stage. The design stage consists of designing the manipulation procedure and the vignettes used to portray the story. Given the aim of investigating the role of TPDI, the manipulation took place within the story itself. The case study was designed to be formed by an introduction, a first session of negotiation (part A) and a second session of negotiation (part B). 
The introduction included background information about the negotiation, the companies, and the negotiators at the table. Company $\mathrm{A}$ is in crisis and risks bankruptcy if it does not find an acquirer, company $\mathrm{B}$ is interested in acquiring it but is lacking the financial resources to do so. Company A is crucial for the economy of its town, therefore the local government is interested in the success of the negotiation. Part A included a series of vignettes conveying the introspective thoughts of the negotiators (the managers of the two companies) and the dialogue at the negotiation table. In this part, the negotiators do not reach an agreement and leave the table postponing the negotiation. In the dialogues the negotiators show several cognitive biases, which influence their interpretations of the situation. Part B presents the second part of the negotiation where unexpectedly the local government enters the negotiation and sits at the table (TPDI). Similar to part A, the second part presents a series of vignettes representing what happened during the negotiation. The dialogues show the TPDI re-framing many biased statements to present the integrative potential of the negotiation. The story ends with a proposal for an integrative agreement by the TPDI. During the writing of the case studies five managers were informally interviewed to comment on the development of the story. Table 1 presents some extracts of the case study.

\section{- - - PLEASE INSERT TABLE 1 ABOUT HERE - - -}

Validation stage. To ensure that the case study was clear, realistic, complete and effective (Rungtusanatham et al., 2011), a panel of experts was formed to independently assess the case study. The panel included 10 faculty members (average of 18.25 years of experience) at a US university who were asked to comment on whether the dialogues showed the desired theoretical constructs. Questions in the form of "to what extent do you think this sentence illustrates (name of the construct)" were asked, requesting answers on a 5-point Likert scale (1 being the lowest and 5 the highest) in order to evaluate the theoretical effectiveness of cognitive biases during the case scenario (Mean $=3.8, S D=1.3$ ). Finally, $\mathrm{PhD}$ students from two universities, one in the US and one in Italy, were asked to assess the revised case study. Suggestions were incorporated in the final version. 


\subsection{Measurement tools}

\subsubsection{Measure of personality}

The ten-item personality inventory (TIPI, Gosling, Rentfrow, \& Swann, 2003) was used to gather information from participants about their personality dimensions. The scale covers personality traits according to the five-factor model (FFM, McCrae \& Costa, 1987), namely extraversion (EXT), agreeableness (AGR), conscientiousness (CON), emotional stability (ES) and openness (OPN). The TIPI measures two items for each personality dimension on a 7-point Likert scale (Gosling et al., 2003). Several previous studies have validated the scale separately (e.g., Caputo, 2014; Ehrhart et al., 2009; Gosling et al., 2003; Volk, Thöni, \& Ruigrok, 2011). The instrument increases administration efficiency and maintains construct validity; it was chosen to reduce transient measurement errors resulting from participant fatigue, frustration, and boredom associated with completing several survey instruments in combination with a lengthy experimental session (Volk et al., 2011). The alpha reliabilities, reported in Table 2, were very similar to the findings by Volk et al. (2011), Ehrhart et al. (2009) and Gosling et al. (2003). With only two items per dimension, the relatively low alphas are to be expected as the computation of Cronbach's alpha is a function of the number of scale items. ${ }^{1}$ Test-retest reliability is therefore a more appropriate reliability measure for such brief scales and Gosling et al. (2003) reported testretest reliability scores for the five TIPI dimensions over a period of six weeks, indicating that the scale provides a stable measure of personality over time.

\section{- - - PLEASE INSERT TABLE 2 ABOUT HERE - - -}

\subsubsection{Measures of perceptions on the biased negotiation process}

In order to determine the perceptions of participants of the parties' behaviors and the negotiation process in the case scenario, a 12-item questionnaire was developed to assess four factors: Claiming value (CLV), Creating value (CRV), Information fairness (IF), and Biased interpretation of information (BII). A 5-point Likert scale was used and participants were asked to rate their level of agreement with a statement ( 1 = "Disagree strongly", 5 = "Agree strongly").

\footnotetext{
1 The explanation of the low Alphas and the reliability of the scale can be found on Prof. Gosling's website at this address: http://gosling.psy.utexas.edu/scales-weve-developed/ten-item-personality-measure-tipi/a-note-on-alpha-reliability-and-factorstructure-in-the-tipi/
} 
The reliability of the questionnaire was validated through a Principal Component Factor Analysis with Varimax rotation, Cronbach's alpha reliabilities and correlations analysis. Reliability values are presented in Table 3.

\section{- - - PLEASE INSERT TABLE 3 ABOUT HERE - - -}

\subsubsection{Questionnaire on the role of the Third Party Direct Intervention (TPDI)}

A set of five questions was developed to investigate the role of the TPDI. A 5-point Likert scale was used and participants were asked to rate their level of agreement with a statement $(1=$ "Disagree strongly", 5 = "Agree strongly"). Two questions asked whether participants thought the situation was likely to be solved and if the intervention of a third party was useful. Three questions asked about the role of the third party, specifically whether it was determinant, whether it helped in overcoming judgmental biases and whether they thought it could lead to an agreement.

\subsubsection{Demographic information}

Seven closed-ended demographic questions asked for age, gender, nationality, educational background, years of working experience, previous formal education or training in negotiation, and previous experience in negotiation.

\subsection{Participants and procedure}

Data were collected from 56 participants among experienced management professionals (working experience: $M=20.14, S D=15.62$ ), selected in order to ensure the representativeness of the dataset for a study involving managers at different levels. Permission was obtained prior to participation in the study and the study took place online on a dedicated website using an ad-hoc data collection software developed for the purpose of the study. The study was run in the English language, as all participants were required to have international experience and speak English fluently. Participants were first presented with demographic questions and the TIPI. Secondly, participants were asked to read the first part of the case scenario and then to answer the questions about their perceptions of the negotiation process. Thirdly, participants were asked to read the second part of the case scenario and then answer again the same questions in reference to this second part. Finally, participants were asked to put themselves in the shoes of the main two 
negotiators and indicate whether they would accept the solution proposed by the third party that ended the case scenario. During the survey, the participants could not skip questions nor come back to modify a previous answer. Each question was presented to them separately to increase participant focus. The average time to complete the survey was approximately 40 minutes.

\subsection{Data analysis}

Data were operationalized and then analyzed with the software SPSS, version 21.0. Descriptive statistics and other corresponding statistical measures (including mean comparison, correlations, ANOVA and logistic regression) were used to investigate the propositions.

\section{Results}

\subsection{Characteristics of participants}

Participants were randomly selected from university institutions and managers' associations distributed across Italy (50.0\%), the United States (41.1\%) and other European Countries (9.0\%). A majority were male (51.8\%), aged between 23 and 79 (Mean $=44.71, \mathrm{SD}=$ $15.35)$, and work experience ranged from 0 to 53 years $($ Mean $=20.14, \mathrm{SD}=15.62)$. Work experience was highly correlated with age $(r=.974, p=.000)$, thus only the former was included in the analyses. A majority of the participants had a master's degree (53.6\%), followed by doctoral degrees (26.8\%), and bachelor's degrees or lower (19.6\%). A majority of the participants had attended a negotiation class (75\%) and had relevant experience in negotiations $(65 \%)$.

\subsection{The impact of TPDI on the negotiation process}

Propositions 1, 2 and 3 were to determine whether TPDI affected the negotiation process, in terms of a less biased interpretation of information, a higher perception of fairness and a creating value approach. Table 4 presents the mean comparisons for the four variables addressing the perceptions of participants on the biased negotiation process before and after the TPDI. The mean score and comparison tests show that CLV was rated lower and CRV higher after the TPDI in the story $(p<.000)$. Similarly IF was rated higher after the intervention $(p<.000)$. BII was rated higher but the mean comparisons were not significant. These results show that participants 
considered TPDI to bring a creative value perspective and fairer perception of the information exchange. Thus, $\mathrm{P} 2$ and $\mathrm{P} 3$ are supported, while $\mathrm{P} 1$ is not.

\section{- - - PLEASE INSERT TABLE 4 ABOUT HERE - - -}

In order to understand differences among the population in terms of demographic characteristics, a series of One-Way ANOVA procedures have been computed by taking into consideration the four dimensions and variables: education, gender and experience or education in negotiations. No statistically significant differences were found, however it is worth noting that education and experience in negotiations showed some differences with reference to Information Fairness $(F=2.011, p=.144)$.

\subsection{The perception on TPDI's role}

Proposition 4 was to determine whether the TPDI was considered to be helpful in overcoming judgmental biases. A question was asked at the end of the case and a vast majority of participants $(80.4 \%)$ rated it as 4 or above $(M=3.98, \mathrm{SD}=0.90)$. Therefore, $\mathrm{P} 4$ was supported.

Propositions 5 and 6 were to determine how managers perceived TPDI, specifically whether they perceived it to be helpful in reaching a solution, and whether TPDI was associated with higher confidence in the possibility of reaching a solution. Table 4 shows the results of the mean ratings for these two questions. The mean scores and comparison tests show that both the likelihood for the situation to be solved and the perceived usefulness of TPDI were rated higher after the TPDI took place $(p<0.10)$. Therefore, P5 and P6 were supported. No significant differences have been found with reference to personality dimensions and demographic characteristics.

\subsection{The output of the case study}

Proposition 7 was to investigate whether individual differences were present at the different stages of the analysis on the negotiation process and the perceptions of TPDI. The analyses to test P1 to P6 did not support any statistically significant findings for individual differences. Therefore, we can conclude that $\mathrm{P} 7$ was not confirmed by the data. 
Proposition 8 was to determine whether individual differences existed in reaching the outcome of the negotiation. Participants were asked whether they would accept the offer from the third party at the end of the case if they were in the position of each of the negotiating parties. In sixty-seven percent of the cases, participants affirmatively answered both questions, meaning an agreement could be reached. A correlation analysis showed a correlation with the perceptions of the usefulness of the third party after its intervention $(r=.309, p=.021)$ and with the level of information fairness $(r=.295, p=.027)$, which means that people who perceived higher information fairness after TPDI are more likely to accept the mediated agreement.

Table 5 shows the results of the binary logistic regression, where the target variable is the "agreement" group. The analysis focuses on results from the bootstrap, whose use is

recommended in binary logistics to increase internal validity (Steyerberg et al., 2001). The model shows a gender effect, namely that the likelihood of reaching an agreement is higher for female subjects than male subjects $(\mathrm{B}=.67, p=.031)$. People with lower levels of education showed more availability to accept the suggested offer $(\mathrm{B}=-.275, p=.011)$, and a higher value in working experience increase the probability of acceptance of the mediated offer $(\mathrm{B}=.04, p=$ $.000)$. In terms of personality traits, $\operatorname{EXT}(\mathrm{B}=-.475, p=.000)$ and $\mathrm{ES}(\mathrm{B}=-.375, p=.001)$ have a negative effect, while AGR $(\mathrm{B}=.391, p=.024)$ plays a positive role. Therefore, $\mathrm{P} 8$ is confirmed.

\section{- - - PLEASE INSERT TABLE 5 ABOUT HERE - - -}

\section{Discussion}

This study examined the role of a novel approach to overcoming judgmental biases in integrative negotiations, the TPDI, through an experimental task performed by experienced managers. The role of third parties in helping to overcome judgmental biases is an underresearched topic in the field of negotiation and results from previous studies showed that the third parties' intervention in negotiations is seen as a possible solution to impasses caused by negotiators' misperceptions. Third party direct intervention is referred to as an intervention from interested entities, originally external, who act as actors in the negotiations. In this view, a third party is a subject which cares both about reaching an agreement and implementing it successfully. In other words, it cares about the quality of the agreement. 
Participants in the study judged the TPDI as having an important influence on the perceived creating value level and fairness level in the negotiation process, but not on the biased interpretation of information. The TPDI, by helping in debriefing the situation and by using integrative behaviors, was perceived to have a positive effect, supporting findings from previous studies (e.g. Arunachalam, Dilla, Shelley, \& Chan, 1998; Lewicki et al., 1992; Raiffa et al., 2002; Sebenius, 1992). Parties showed the fixed-pie error along the negotiation process, which, as predicted, had an effect on the perception of fairness (e.g., Mumpower, Sheffield, Darling, \& Miller, 2004; Patton \& Balakrishnan, 2010; Thompson \& Hastie, 1990; Thompson \& Loewenstein, 1992). Thus, the TPDI's action in the case study involved framing techniques to de-bias negotiators. These results are consistent with previous studies analyzing the effects of framing on perceptions of fairness (Chang, Cheng, \& Trotman, 2008). Although a gender effect was found in previous similar studies (Eriksson \& Sandberg, 2012; Kulik \& Olekalns, 2012; Semnani-Azad \& Adair, 2011; Volkema, 2004), participants in this study did not show any individual differences in their responses. However, further research should investigate the relationship between previous education and experience in negotiation as findings, although not significant, show the possibility for such an effect to exist.

Participants in the study also perceived the TPDI as useful and determinant to overcoming judgmental biases, and then leading to an agreement, Moreover, participants showed a change of perceptions resulting in an increased positive view on the intervention of an external party after the TPDI happened. Finally, participants showed inclination to accept the proposed agreement after the TPDI. A correlation was found with previous perceptions on the TPDI. Specifically, the acceptance of the agreement was correlated with considerations about how useful the TPDI was perceived and information fairness. These findings support previous studies that called for external intervention to reach integrative agreements (Conlon, Carnevale, \& Ross, 1994; Delerue, 2005; Sebenius, 1992). Perception of fairness was largely associated with difficulties in reaching an agreement and external parties were seen to overcome such an issue. This study's findings confirm previous studies (Karambayya \& Brett, 1989; Thompson \& Loewenstein, 1992) and portray TPDI as an effective countermeasure.

There are certain individual differences regarding the acceptance of the agreement, namely in terms of personality, gender, education and experience. Participants in this study showed a gender effect, as predicted by some recent studies (Eriksson \& Sandberg, 2012; Kulik \& 
Olekalns, 2012; Semnani-Azad \& Adair, 2011). There were more females than males in the group of subjects that agreed on the proposal from the third party. People with lower levels of education showed more willingness to accept the mediated offer than people with higher education, while work experience had a limited effect. Learning and experience have been considered to enhance negotiators' decision-making processes by some scholars (Ritov, 1996; Thompson \& Hastie, 1990). Others have stated that over time negotiators may become overconfident in their negotiating abilities, may put more trust in heuristics, and tend to avoid negotiated - and mediated - settlements (Larrick \& Wu, 2007).

Other individual differences were related to personality. Personality has been widely studied in negotiation, generating inconsistent support for a personality and negotiation relationship. Negotiation researchers have been attempting different methods to build actionable knowledge in this area (Sharma et al., 2013). While suggestions regarding the impact of personality on negotiations are intuitively appealing, many studies have provided uneven evidence for such relationships (Sharma et al., 2013). This inconsistency has made researchers skeptical of such relationships and led them to contend that these inconsistencies are partly due to the utilization of bargainer variables that are conveniently available, instead of being conceptually related to negotiations (Barry \& Friedman, 1998; Sharma et al., 2013).

Several experiments have provided evidence that negotiators make systematic errors in personality-trait attributions for the bargaining behaviors of their counterparts. Although basic negotiation behavior is highly determined by bargaining positions, negotiators primarily interpret their counterpart's behavior in terms of the counterpart's personality, such as his or her level of cooperativeness or agreeableness (Morris \& Fu, 2001). How involved parties define negotiation determines how they approach the negotiation. According to social cognition theory (Morris \& $\mathrm{Fu}, 2001$ ), a negotiator's personality affects how the negotiator defines the negotiation situation and further forms different understandings. In addition, $\mathrm{Ma}$ (2008) presented a model where the negotiator's personality is expected to have a direct impact on negotiator cognitions through which personality then indirectly affects the negotiator's behaviors and outcomes.

The personality traits of extraversion, agreeableness and emotional stability showed significant interactions with the disposition to accept the suggested agreement, and then to reach a negotiated settlement. Extraversion seems to be a predictor for the rejection of the proposal. This result is consistent the fact that values in the trait of extraversion have been found to be 
negatively correlated with the perceptions of information fairness and creating value. Indeed, a lower level of perception of fairness has been found to be a predictor for impasse in negotiation (Mumpower et al., 2004; Thompson \& Hastie, 1990; Thompson \& Loewenstein, 1992).

Negotiators high in agreeableness have been found to be best suited to integrative negotiations and to prefer negotiation and disengagement tactics as better choices than power assertion tactics (Dimotakis, Conlon, \& Ilies, 2012). The trait of agreeableness has been found to be positively related to styles such as Avoiding and Compromising, and it predicts effective negotiation performance (Ana-Paula, Gonzalo, \& Damaso, 2012). These results have been confirmed by the present study. In fact, subjects willing to accept the mediated proposal, and thus reach an agreement, show higher values of agreeableness than those unwilling to.

Emotional stability is positively related to integrative styles of negotiation (Ana-Paula et al., 2012). In this study, subjects with higher values of emotional stability perceived a lower fairness in the absence of the third party and higher claiming value tactics after the intervention of the third party. Consistent with the characteristics of the trait, it was not found to be associated with any change in perceptions. Contradictory to previous studies, emotional stability was negatively correlated with the disposition to accept the mediated offer. As with the trait of extraversion, the results from the present study are consistent with the previous findings relating to information fairness perception. In fact, a lower level of perception of fairness has been found to be a predictor for impasse in negotiation (Mumpower et al., 2004; Thompson \& Hastie, 1990; Thompson \& Loewenstein, 1992).

\section{Conclusions}

This study investigated managers' perceptions of third party direct intervention in overcoming judgmental biases to reach integrative agreements. Negotiations are essential and fundamental moments of life. Therefore, improving negotiation skills, as well as increasing the ability to negotiate effectively, is crucial in managerial, political, and business contexts. Simon's bounded rationality (1972) acknowledges that individuals, while attempting to make rational decisions, often lack important information and the relevant criteria of problems, and prior literature in management and psychology has demonstrated that managers and negotiators do not always act rationally. 
The unique contributions of this study are manifold. First is the understanding of how a TPDI in a negotiation is perceived regarding its role in helping to overcome judgmental biases of the negotiators. The TPDI was found to have an important influence on the perceived creating value level and fairness level in the negotiation process, as well as on the possibility of reaching a negotiated settlement, by helping to debrief the situation and by using integrative behavior. This intervention also helped the parties to overcome the fixed-pie error, showed throughout the negotiation process, which resulted in affecting the perception of fairness. In addition, the vast majority of participants perceived the third party direct intervention to be useful and determinant in overcoming judgmental biases, and accepted the mediated agreement.

Second is the contribution to the literature on individual differences, in terms of personality and demographics in negotiations. The roles of gender and education were found to be controversial. While no gender effect was found with reference to perceptions of TPDI and the negotiation process, a gender effect was found with regard to TPDI and the outcome of the negotiation, which is an interesting result and an issue to be further researched. Moreover, managers' high values in extraversion and emotional stability reduced the likelihood of reaching an agreement, while agreeableness increased it.

Third is the methodological contribution of this study to the literature on negotiations. Indeed, research in this field has been criticized for adopting experimental settings involving students, often with limited or no working experience. Additionally, the experimental designs in negotiation research were often considered to be too far away from reality by practitioners. This study contributes to solve both issues. It investigated a sample of managers with an average of over twenty years of working experience. Additionally, it developed a novel approach to using scenarios and vignettes in negotiation research, by creating and validating an original case study and borrowing rigorous methodologies from other fields.

Yet, the nature of this study was exploratory as it aimed to analyze a novel approach for integrative negotiations with novel methodologies. This resulted in both limitations and opportunities for future research and practice to build upon the results. For example, future research should analyze the effects of specific education and experience in negotiation, as results showed differences in perceptions between subjects with and without specific education or experience in negotiations. More research needs to be done to investigate the role played by personality factors in the perception of direct third party intervention. These results do not allow 
for a systematic modeling of this issue. Finally, the use of the developed case study and similar methods with multiple and diverse samples could help in refining and strengthening the methodology as well as increasing our knowledge of how to overcome biases to reach integrative agreements. 


\section{References}

Ackermann, F., \& Eden, C. (2011). Negotiation in Strategy Making Teams: Group Support Systems and the Process of Cognitive Change. Group Decision and Negotiation, 20(3), 293-314.

Ana-Paula, M., Gonzalo, S., \& Damaso, R. (2012). Conflict management styles, personality factors and effectiveness in the negotiation. Revista de Psicologia Social, 27(1), 97-109.

Arunachalam, V., Dilla, W., Shelley, M., \& Chan, C. (1998). Market Alternatives, Third Party Intervention, and Third Party Informedness in Negotiation. Group Decision and Negotiation, 7(2), 81-107.

Barrick, M. R., \& Mount, M. K. (1991). The Big Five personality dimensions and job performance: a meta-analysis. Personnel Psychology, 44(1), 1-27.

Barry, B., \& Friedman, R. A. (1998). Bargainer characteristics in distributive and integrative negotiation. Journal of Personality and Social Psychology, 74(2), 345-359.

Bazerman, M. H., \& Moore, D. (2013). Judgment in Managerial Decision Making (5th ed.). New York, NY: John Wiley \& Sons.

Caputo, A. (2012). Integrative Agreements in Multilateral Negotiations: The Case of Fiat and Chrysler. International Journal of Business and Social Sciences, 3(12), 167-180.

Caputo, A. (2013a). A Literature Review of Cognitive Biases in Negotiation Processes. International Journal of Conflict Management, 24(4), 274-398.

Caputo, A. (2013b). The Third Who Joins a Negotiation: a Systematic Review of the Literature. International Journal of Business and Globalisation, 10(3), 256-277.

Caputo, A. (2014). Relevant information, personality traits and anchoring effect. International Journal of Management \& Decision Making, 13(1), 62-76.

Caputo, A. (2015). Fiat and Chrysler, negotiating for survival. Strategic Direction, 31(1), 27-29.

Chan, S. H., \& Ng, T. S. (2016). Ethical negotiation values of Chinese negotiators. Journal of Business Research, 69(2), 823-830.

Chang, L., Cheng, M., \& Trotman, K. T. (2008). The effect of framing and negotiation partner's objective on judgments about negotiated transfer prices. Accounting, Organizations and Society, 33(7/8), 704.

Conlon, D. E., Carnevale, P., \& Ross, W. H. (1994). The Influence of Third Party Power and Suggestions on Negotiations: The Surface Value of a Compromise. Journal of Applied 
Social Psychology, 24(12), 1084-1113.

De Dreu, C. K. W. (2003). Time pressure and closing of the mind in negotiation. Organizational Behavior and Human Decision Processes, 91, 280-295.

Delerue, H. (2005). Conflict resolution mechanisms, trust and perception of conflict in contractual agreements. Journal of General Management, 30(4), 11-26.

Dimotakis, N., Conlon, D., \& Ilies, R. (2012). The Mind and Heart (Literally) of the Negotiator: Personality and Contextual Determinants of Experiential Reactions and Economic Outcomes in Negotiation. Journal of Applied Physiology, 97(1), 183-193.

Ehrhart, M. G., Ehrhart, K. H., Roesch, S. C., Chung-Herrera, B. G., Nadler, K., \& Bradshaw, K. (2009). Testing the latent factor structure and construct validity of the Ten-Item Personality Inventory. Personality \& Individual Differences, 47(8), 900-905.

Eriksson, K. H., \& Sandberg, A. (2012). Gender Differences in Initiation of Negotiation: Does the Gender of the Negotiation Counterpart Matter? Negotiation Journal, 28(4), 407-428.

Giacomantonio, M., De Dreu, C. K. W., \& Mannetti, L. (2010). Now you see it, now you don't: interests, issues, and psychological distance in integrative negotiation. Journal of Personality and Social Psychology, 98(5), 761.

Gosling, S. D., Rentfrow, P. J., \& Swann, W. B. (2003). A very brief measure of the Big-Five personality domains. Journal of Research in Personality, 37(6), 504-528.

Güth, W., Schmittberger, R., \& Schwarze, B. (1982). An experimental analysis of ultimatum bargaining. Journal of Economic Behavior \& Organization, 3(4), 367-388.

Harinck, F., \& De Dreu, C. K. W. (2004). Negotiating interests or values and reaching integrative agreements: the importance of time pressure and temporary impasses. European Journal of Social Psychology, 34(5), 595-611.

Herbst, U., \& Schwarz, S. (2011). How valid is negotiation research based on student sample groups? New insights into a long-standing controversy. Negotiation Journal, 27(2), 147170.

Jackson, E. (1952). Meetings of Minds. New York: McGraw Hill.

Karambayya, R., \& Brett, J. M. (1989). Managers Handling Disputes: Third-Party Roles And Perceptions of Fairness. Academy of Management Journal, 32(4), 687.

Keashly, L., Fisher, R. J., \& Grant, P. R. (1993). The Comparative Utility of Third Party Consultation and Mediation Within a Complex Simulation of Intergroup Conflict. Human 
Relations, 46(3), 371-393.

Kramer, R. M. (1991). The More the Merrier? Social Psychological Aspects of Multiparty Negotiations in Organizations. In M. Bazerman, R. J. Lewicki, \& B. H. Sheppard (Eds.), Research on Negotiation in Organizations: Handbook of Negotiation Research. Greenwich: JAI Press.

Kulik, C. T., \& Olekalns, M. (2012). Negotiating the Gender Divide: Lessons From the Negotiation and Organizational Behavior Literatures. Journal of Management, 38(4), 1387Larrick, R. P., \& Wu, G. (2007). Claiming a Large Slice of a Small Pie: Asymmetric Disconfirmation in Negotiation. Journal of Personality and Social Psychology, 93(2), 212.

Lax, D. A., \& Sebenius, J. K. (1986). The Manager as Negotiator: Bargaining for Cooperation and Competitive Gain. New York: Macmillan.

Lewicki, R. J., Saunders, D., \& Barry, B. (2014). Negotiation (7th ed.). New York: McGraw Hill.

Lewicki, R. J., Weiss, S., \& Lewin, D. (1992). Models of Conflict, Negotiation and Third Party Intervention: A Review and Synthesis. Journal of Organizational Behavior, 13(3), 209.

Ma, Z. (2008). Personality and negotiation revisited: toward a cognitive model of dyadic negotiation: MRN. Management Research News, 31(10), 774-790.

McCrae, R., \& Costa, P. T. J. (1987). Validation of the five-factor model of personality across instruments and observers. Journal of Personality and Social Psychology, 52(1), 81-90.

Moran, S., \& Ritov, I. (2007). Experience in integrative negotiations: What needs to be learned? Journal of Experimental Social Psychology, 43(1), 77-90.

Morris, M. W., \& Fu, H. Y. (2001). How does culture influence conflict resolution: a dynamic constructivist analysis. Social Cognition, 19(3), 324-349.

Mumpower, J. L., Sheffield, J., Darling, T. A., \& Miller, R. G. (2004). The Accuracy of PostNegotiation Estimates of the Other Negotiator's Payoff. Group Decision and Negotiation, $13(3), 259$.

Murninghan, J. K., \& Brass, D. (1991). Intraorganizational Coalitions. In R. J. Lewicki, B. H. Sheppard, \& M. Bazerman (Eds.), Research on Negotiation in Organizations. Greenwich: JAI Press.

Neale, M. A., \& Bazerman, M. H. (1985). The Effects of Framing and Negotiator Overconfidence on Bargaining Behaviors and Outcomes. Academy of Management Journal, 
28(1), 34 .

Neale, M. A., \& Bazerman, M. H. (1991). Cognition and rationality in negotiation. New York: The Free Press.

Ness, H., \& Haugland, S. A. (2005). The evolution of governance mechanisms and negotiation strategies in fixed-duration interfirm relationships. Journal of Business Research, 58(9), $1226-1239$.

Newell, A., \& Simon, H. A. (1972). Human problem solving. Englewood Cliffs, NJ: Prentice Hall.

Ogliastri, E., \& Quintanilla, C. (2016). Building cross-cultural negotiation prototypes in Latin American contexts from foreign executives' perceptions. Journal of Business Research, $69(2), 452-458$.

Patton, C., \& Balakrishnan, P. V. S. (2010). The impact of expectation of future negotiation interaction on bargaining processes and outcomes. Journal of Business Research, 63(8), 809-816.

Pruitt, D. G. (2011). A Critique of Experimental Research on Negotiation. In IACM 24TH Annual Conference Paper.

Raiffa, H., Richardson, J., \& Metcalfe, D. (2002). Negotiation Analysis: the Science and Art of Collaborative Decision Making. Cambridge (MA): The Belknap Press of Harvard University Press.

Ritov, I. (1996). Anchoring in simulated competitive market negotiation. Organizational Behavior and Human Decision Processes, 67(1), 16-25.

Rungtusanatham, M., Wallin, C., \& Eckerd, S. (2011). The vignette in a scenario-based roleplaying experiment. Journal of Supply Chain Management, 47(3), 9-16.

Schei, V. (2008). Are Individualistic Orientations Collectively Valuable in Group Negotiations? Group Processes \& Intergroup Relations, 11(3), 371-385.

Sebenius, J. K. (1983). Neogitation Arithmetic: adding and subtracting issues and parties. International Organization, 37(2), 281-316.

Sebenius, J. K. (1992). Negotiation Analysis: A Characterization and Review. Management Science, 38(1), 18-38.

Semnani-Azad, Z., \& Adair, W. L. (2011). The Display of "Dominant" Nonverbal Cues in Negotiation: The Role of Culture and Gender. International Negotiation, 16(3), 451-479. 
Sharma, S., Bottom, W. P., \& Elfenbein, H. A. (2013). On the role of personality, cognitive ability, and emotional intelligence in predicting negotiation outcomes A meta-analysis. Organizational Psychology Review, 3(4), 293-336.

Simon, H. A. (1972). Theories of bounded rationality. Decision and Organization, 1, 161-176.

Stevens, C. M. (1963). Strategy and Collective Bargaining Negotiation. New York: McGraw Hill.

Steyerberg, E. W., Harrell, F. E. J., Borsboom, G. J., Eijkemans, M. J., Vergouwe, Y., \& Habbema, J. D. (2001). Internal validation of predictive models: Efficiency of some procedures for logistic regression analysis. Journal of Clinical Epidemiology, 54(8), 774781.

Thompson, L. (1990). Negotiation behavior and outcomes: empirical evidence and theoretical issues. Psychological Bulletin, 108, 515-532.

Thompson, L., \& Hastie, R. (1990). Social Perception in Negotiation. Organizational Behavior and Human Decision Processes, 47(1), 98-123.

Thompson, L., \& Loewenstein, G. (1992). Egocentric Interpretations of Fairness and Interpersonal Conflict. Organizational Behavior and Human Decision Processes, 51(2), 176-197.

Thompson, L., Nadler, J., \& Lount, R. B. (2006). Judgmental Biases in Conflict Resolution and How to Overcome Them. In M. Deutsch \& P. Coleman (Eds.), The Handbook of Conflict Resolution: Theory and Practice (2nd Edition). San Francisco: Jossey Bass.

Traavik, L. E. M. (2011). Is bigger better? Dyadic and multiparty integrative negotiations. International Journal of Conflict Management, 22(2), 190.

Volk, S., Thöni, C., \& Ruigrok, W. (2011). Personality, personal values and cooperation preferences in public goods games: A longitudinal study. Personality and Individual Differences, 50(6), 810-815.

Volkema, R. (2004). Demographic, cultural, and economic predictors of perceived ethicality of negotiation behavior: A nine-country analysis. Journal of Business Research, 57(1), 69-78.

Walton, R. E., \& McKersie, R. B. (1965). A Behavioral Theory of Labor Negotiations. Beverly Hills, CA: Sage Publications.

Zartman, W. I. (2008). Bias, Prenegotiation and Leverage in Mediation. International Negotiation, 13(3), 305. 


\section{Figures and Tables}

Figure 1 - The third party direct intervention

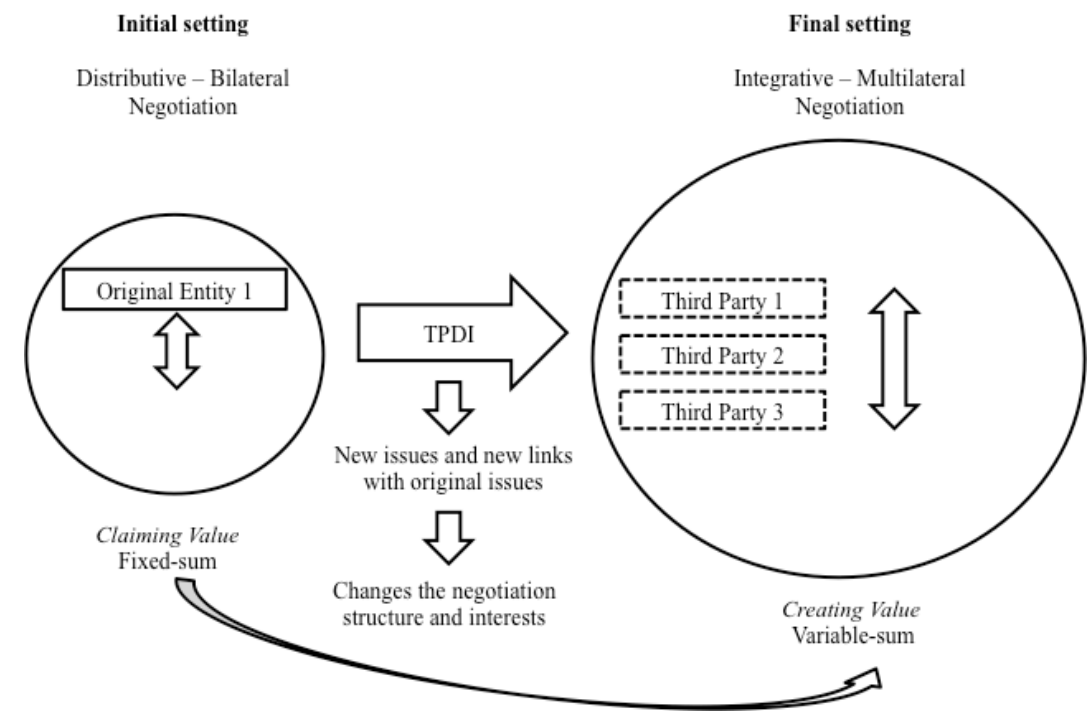

Table 1 - Extracts from the case

\begin{tabular}{|c|c|c|}
\hline \multirow[t]{2}{*}{ Background } & Company A & $\begin{array}{l}\text { Second largest business of the town. Managerial mistakes, a large debt and technology } \\
\text { obsolescence put the company in financial crisis, causing the company to laid off } 50 \% \text { of } \\
\text { workforce, which increased the town's economic recession. The company is now facing } \\
\text { bankruptcy in one month. Only hope for the company, employees and the town is to be } \\
\text { acquired. The stand-alone business has a negative value but if the company is integrated } \\
\text { with a larger organization it would turn into a more profitable business. }\end{array}$ \\
\hline & Company B & $\begin{array}{l}\text { Leading company from the region. Because of its successful market strategies and its } \\
\text { outstanding technology, the company has been growing over the last ten years. Yet, the } \\
\text { company has a large debt used to acquire several small players. Company A would be a } \\
\text { perfect fit from industrial perspective but the company does not have sufficient financial } \\
\text { resources. }\end{array}$ \\
\hline \multirow[t]{2}{*}{$\begin{array}{l}\text { Examples of } \\
\text { biases }\end{array}$} & $\begin{array}{l}\text { Framing and } \\
\text { Fixed-pie } \\
\text { Anchoring }\end{array}$ & $\begin{array}{l}\text { "But, there is only one problem", thought Ted while shaving off on the morning of the } \\
\text { meeting with Jim, "the money! We won't have the money to pay for this company. } \\
\text { Jim entered the room thinking, "I have no chance, I need this guy to pay our debt. That's } \\
\text { your goal, Jim you can do it". }\end{array}$ \\
\hline & Self-serving & $\begin{array}{l}\text { Jim: "Once you integrate the companies, I am sure you will have so much cash flow to } \\
\text { repay every single dollar of our debt." }\end{array}$ \\
\hline $\begin{array}{l}\text { Example of } \\
\text { de-bias by } \\
\text { TPDI }\end{array}$ & Re-framing & $\begin{array}{l}\text { Mayor: "Listen to me, Jim. I understand that you want to focus just on one issue, the price, } \\
\text { but by doing this you are missing other issues. You forget how this agreement could be a } \\
\text { win-win situation for everyone." }\end{array}$ \\
\hline
\end{tabular}


Table 2 - Zero-order correlation, reliability and means for personality factors.

\begin{tabular}{|c|c|c|c|c|c|c|c|c|c|c|}
\hline \multicolumn{11}{|l|}{ Zero-order correlation } \\
\hline Variable & Alpha & Mean & $\mathrm{SD}$ & 1 & 2 & 3 & 4 & 5 & 6 & 7 \\
\hline 1. Gender & - & & & 1 & & & & & & \\
\hline 2. Age & - & & & $-.30 *$ & 1 & & & & & \\
\hline 3. Extraversion & 0.67 & 4.71 & 1.39 & .20 & .01 & 1 & & & & \\
\hline 4. Agreeableness & 0.23 & 5.24 & 1.10 & -.01 & .21 & .08 & 1 & & & \\
\hline 5. Conscientiousness & 0.64 & 5.74 & 1.17 & -.06 & .20 & $-.27 *$ & .04 & 1 & & \\
\hline 6. Emotional stability & 0.55 & 5.10 & 1.37 & $-.30^{*}$ & $.33^{*}$ & $-.33^{*}$ & .18 & $.44 * *$ & 1 & \\
\hline 7. Openness to experience & 0.36 & 5.87 & 0.93 & -.16 & .21 & $.32 *$ & .11 & -.19 & -.08 & 1 \\
\hline
\end{tabular}

$* p<0.05$

$* * p>0.01$

Table 3 - Value domains from Principal Components Factor Analysis

\begin{tabular}{ll}
\hline Value domains for terminal values & Marker values in order of the level of the factor loadings \\
\hline $\begin{array}{l}\text { Claiming value } \\
\text { Part } A: \alpha=0.773, M=3.82, S D=0.71 ;\end{array}$ & $\begin{array}{l}\text { I think the parties' orientation was competitive rather than collaborative. } \\
\text { I think the parties tried to maximize own share of benefits, rather than to } \\
\text { increase benefits for both sides. } \\
\text { I think the parties focused more on positions than interests. }\end{array}$ \\
\hline Creating value & I think Jim is considering all the facets of the situation. \\
(Part $A: \alpha=0.709, M=2.76, S D=0.77 ;$ & I think Ted is considering all the facets of the situation. \\
Part $B: \alpha=0.509, M=3.11, S D=0.65)$ & I think the parties focused more on positions than interests. (Reverse) \\
\hline Information fairness & I think the overall information disclosure was fair. \\
(Part $A: \alpha=0.629, M=3.23, S D=0.66 ;$ & I think Jim's information disclosure was fair. \\
Part $B: \alpha=0.580, M=3.54, S D=0.56)$ & I think Ted's information disclosure was fair. \\
\hline Biased interpretation of information & I think Jim interpreted the information in a limited fashion. \\
Part $A: \alpha=0.634, M=2.90, S D=0.64 ;$ & I think Ted interpreted the information in a limited fashion. \\
Part $B: \alpha=0.558, M=2.98, S D=0.58)$ & I think Jim's communication style is open. (Reverse) \\
& I think Ted's communication style is open. (Reverse) \\
\hline
\end{tabular}

Note: value domains obtained from principal components factor analysis with Varimax rotation. Cronbach's alphas $(\alpha)$, mean scores (M) and standard deviations (SD) in parentheses.

Table 4 - Mean comparisons for perceptions on the biased negotiation process.

\begin{tabular}{llll}
\hline & TPDI & & \\
\hline Variable & Before & $t$-test 2 tail sig. \\
\hline Claiming Value (CLV) & 3.82 & 3.17 & .000 \\
Creating Value (CRV) & 2.76 & 3.11 & .000 \\
Information Fairness (IF) & 3.23 & 3.53 & .000 \\
Biased Interpretation of Information (BII) & 2.90 & 2.98 & .332 \\
Situation likely to be solved & 3.08 & 3.96 & .000 \\
TPDI would be/was useful & 3.98 & 4.25 & .057 \\
\hline
\end{tabular}


Table 5 - Result of the binary logistic regression.

\begin{tabular}{|c|c|c|c|c|}
\hline \multicolumn{5}{|l|}{ Variables in the equation } \\
\hline & $\mathrm{B}$ & S.E. & Sig. & $\operatorname{Exp}(\mathrm{B})$ \\
\hline Gender & 0.67 & 0.327 & 0.031 & 1.954 \\
\hline Education & -0.275 & 0.122 & 0.011 & 0.759 \\
\hline Working Experience & 0.04 & 0.006 & 0 & 1.041 \\
\hline Education or Experience in Negotiation & -0.249 & 0.156 & 0.1 & 0.779 \\
\hline Extraversion (EXT) & -0.475 & 0.114 & 0 & 0.622 \\
\hline Agreeableness (AGR) & 0.391 & 0.19 & 0.024 & 1.479 \\
\hline Conscientiousness (CON) & 0.03 & 0.156 & 0.824 & 1.031 \\
\hline Emotional stability (ES) & -0.375 & 0.163 & 0.001 & 0.687 \\
\hline Openness to experience (OPN) & 0.109 & 0.196 & 0.56 & 1.115 \\
\hline Constant & 2.188 & 1.404 & 0.104 & 8.914 \\
\hline $\begin{array}{l}\text { Model statistics } \\
N=56 \\
-2 \text { Log likelihood }=61.072 \\
\text { Correct classification } \%=72.7 \\
\text { Nagelkerke } R^{2}=.199\end{array}$ & & & & \\
\hline
\end{tabular}

